\title{
PENATAAN DESA BAWOMATALUO SEBAGAI DESA WISATA BUDAYA DENGAN PENDEKATAN KONSERVASI
}

\author{
Juntrisnawati Loi ${ }^{1}$ \\ ${ }^{1}$ Magister Teknik Perencanaan Wilayah dan Kota - Real Estat, Universitas Tarumanagara \\ Email: juntrisloi@yahoo.com
}

Masuk: 22-11-2019, revisi: 26-05-2020, diterima untuk diterbitkan: 27-05-2020

\begin{abstract}
ABSTRAK
Desa Bawomataluo merupakan desa wisata yang berada di Kecamatan Fanayama, Kabupaten Nias Selatan, Provinsi Sumatera Utara. Keberadaan Desa Bawomataluo sebagai pewaris dan pelestari yang aktif menjalankan kearifankearifan lokal sangat berpotensi dalam mempertahankan identitas budaya serta menjadi objek wisata yang banyak dikunjungi oleh para wisatawan. Terdapat banyak bangunan rumah tradisional dan batu megalit yang berfungsi sebagai penanda desa mengalami kerusakan disebabkan oleh berbagai faktor. Salah satunya yaitu mulai banyaknya bangunan rumah tradisional yang kehilangan keasliannya dan mengarah kepada bangunan modern dengan menggunakan bahan-bahan material beton dan atap rumah berupa seng. Kondisi ini menyebabkan bangunan tradisional tidak lagi dapat memenuhi fungsinya dalam kondisi yang wajar. Serta kurang aktifnya keterlibatan masyarakat dan pemerintah lokal dalam memelihara serta mempertahankan warisan budaya dan sistem kehidupan desa yang berlandaskan nilai-nilai budaya dan adat istiadat yang mulai terlupakan. Salah satu upaya pelestarian Desa Bawomataluo adalah dengan melakukan penataan desa adat dengan pendekatan konservasi, dilakukan untuk menghidupkan kembali dan mempertahankan aktivitas budaya masyarakat setempat baik fisik maupun non-fisik, seperti membangun atau memperbaiki bangunan tradisional, serta menambah kelengkapan fasilitas penunjang desa sebagai desa wisata. Penentuan tindakan konservasi terhadap setiap bangunan rumah tradisional dan batu megalit dilihat berdasarkan pada kondisi eksisiting, keutuhan dan keasliaannya, serta perubahan yang terjadi baik secara fisik maupun fungsi. Hasil studi ini berupa hasil bentuk - bentuk tindakan konservasi terhadap bangunan adat dan batu megalit, serta berupa Masterplan yang dapat dikembangkan menjadi kawasan wisata budaya. Masterplan kawasan wisata terbagi dalam tiga zona, yaitu zona inti (konservasi), zona penyangga, zona pengembangan untuk pengembangan sosial ekonomi dan budaya masyarakat.
\end{abstract}

Kata Kunci: Cagar Budaya; Desa Wisata; Konservasi; Penataan

\begin{abstract}
Bawomataluo Village is a tourist village located in Fanayama sub-district, South Nias Regency, North Sumatra Province. The existence of this Bawomataluwo Village as an heir and preservation that actively run the local wisdom very potential in maintaining cultural identity and become a tourist attraction visited by many tourists. Bawomataluwo Village has many traditional houses and megaliths. There are many traditional house buildings and megalith stones that function as markers of the village experiencing damage caused by various factors. One of them traditional house have lost its authenticity and lead to modern buildings using materials of concrete materials and roof of the house in the form of zinc. This condition makes the traditional building can no longer fulfill its function under reasonable conditions and the inactivity of the community and local government in maintaining existing cultural heritage and village life systems based on cultural values to be forgotten. One of the efforts in preserving Bawomataluo Village is by development village with conservation approach. This conservation objective is to revive and maintain the cultural activities of local communities, both physical and non-physical, such as repairing traditional buildings, and adding to the completeness of village supporting facilities as a village tourism. The determination of conservation measures against each traditional building and megalith stone is seen based on the existing condition, its integrity and its authenticity, as well as changes occurring both physically and in the function of traditional house building. This study result are conservation action to traditional buildings, megaliths and masterplan that can be developed into a culture tourism area. This masterplan is divided into three zones like core zone (conservation), buffer zone and development zone for social economy development and community culture.
\end{abstract}

Keywords: Conservation; Cultural Heritage; Development; Village Tourism 


\section{PENDAHULUAN}

\section{Latar Belakang}

Indonesia merupakan negara yang kaya akan warisan seni dan budaya. Warisan kebudayaan Indonesia yang bermacam - macam disebabkan oleh banyak faktor antara lain karena suku bangsa Indonesia yang beragam dan tingkat kreatifitas masyarakat Indonesia yang tinggi dalam bidang kesenian dan kebudayaan, sehingga menghasilkan warisan kebudayaan yang beragam salah satunya adalah terbentukya desa-desa adat. Dengan demikian, desa adat merupakan bagian dari kekayaan bangsa yang wajib dilestarikan dan salah satu upaya pelestariannya adalah dengan melakukan penataan desa adat dengan pendekatan konservasi.

Kabupaten Nias Selatan merupakan salah satu dari 4 kabupaten yang ada di Nias yang memiliki 40 daya tarik wisata yaitu wisata alam dan wisata budaya. Salah satu wisata budaya yang terkenal di Nias Selatan adalah Desa Bawomataluo dan merupakan salah satu kawasan strategis di Nias Selatan berdasarkan kepentingan sosial budaya. Desa Bawomataluo merupakan salah satu warisan budaya dunia yang telah diusulkan oleh UNESCO sejak tahun 2009. Saat ini, Tim Ahli Cagar Budaya Nasional (TACBN) telah menyetujui Desa Bawomataluo menjadi Cagar Budaya Nasional. Penetapan Desa Bawomataluo sebagai Cagar Budaya Nasional merupakan salah satu syarat untuk mengajukan agar ditetapkan sebagai Warisan Dunia di UNESCO, yang saat ini sedang diupayakan oleh Tim Ahli Universitas Gadjah Mada (UGM) dan sejumlah universitas dari Jepang sejak 2011. Desa Bawomataluo merupakan salah satu desa Adat yang terkenal di Kabupaten Nias Selatan tepatnya berada di Kecamatan Fanayama. Desa Bawomataluoa sudah ada sejak zaman megalitikum dengan luas area desa adat 5 ha dan berada diatas bukit. Desa Bawomataluo masih sangat asli, lengkap dengan tradisi-tradisinya, seperti tradisi lompat batu, tari perang dan batu-batu peninggalan megalitikum.

Gambaran Desa Bawomataluo terlihat seperti lahan luas yang rata dengan batu dan dipenuhi dengan deretan rumah-rumah adat tradisional yang terbuat dari kayu dan beratapkan rumbia berbentuk pelana runcing yang melekat pada rumah disampingnya, sehingga rumah-rumah adat tradisional tersebut berderet. Saat ini jumlah rumah adat di desa yang masih berbentuk rumah tradisional (Omo Hada) berjumlah 125 rumah masyarakat, satu unit Omo Sebua (rumah adat besar/rumah raja yang berada di tengah-tengah desa) dan bale pertemuan (Omo Bale). Saat ini masyarakat Desa Bawomataluo tetap mengembangkan kearifan-kearifan lokal yang tetap dipelihara dan diwariskan, seperti yang terwujud dalam bentuk rumah adat, tradisi lompat batu dan tari perang serta budaya peninggalan megalitikum yang menjadi identitas dari Desa Bawomataluo. Hal ini menunjukan bahwa fungsi utama keberadaan rumah adat dan peninggalan megalitikum menjadi hal penting bagi masyarakat desa sebagai upaya untuk memelihara sistem kebudayaan di desa mereka.

Desa Bawomataluo memiliki banyak bangunan rumah tradisional dan batu megalit yang berfungsi sebagai penanda desa yang mengalami kerusakan disebabkan oleh berbagai faktor. Salah satunya yaitu mulai banyaknya bangunan rumah tradisional yang kehilangan keasliannya dan mengarah kepada bangunan modern dengan menggunakan bahan-bahan material beton dan atap rumah berupa seng. Kondisi ini menyebabkan bangunan tradisional tidak lagi dapat memenuhi fungsinya dalam kondisi yang wajar. Serta kurang aktifnya keterlibatan masyarakat dan pemerintah lokal dalam memelihara dan mempertahankan warisan budaya yang ada dan sistem kehidupan desa yang berlandaskan nilai-nilai budaya dan adat istiadat yang mulai terlupakan. 
Salah satu upaya pelestarian Desa Bawomataluo adalah dengan melakukan penataan desa adat dengan pendekatan konservasi, dilakukan untuk menghidupkan kembali dan mempertahankan aktivitas budaya masyarakat setempat, baik fisik maupun non-fisik, seperti membangun atau memperbaiki bangunan adat, kelengkapan adat serta ritual adat, serta menambah kelengkapan fasilitas penunjang desa sebagai desa wisata sehingga memberikan kenyamanan bagi para pengunjung dan tetap menjaga keutuhan desa sebagai desa wisata yang memiliki nilai-nilai budaya dan adat istiadat.

Pelaksanaan Konservasi terkait rencana penataan di Desa Bawomataluo meliputi dengan penentuan tindakan konservasi terhadap setiap bangunan rumah tradisional dan batu megalit dilihat berdasarkan pada kondisi eksisiting, keutuhan dan keasliaannya, serta perubahan yang terjadi baik secara fisik maupun fungsi bangunan rumah tradisonal.

\section{Rumusan Masalah}

Berdasarkan penjabaran latar belakang yang telah disampaikan di atas dapat diketahui telah terjadi penurunan kualitas lingkungan desa adat sebagai tempat tujuan wisata. Dapat dilihat permasalahan dari segi fisik seperti banyaknya bangunan yang rusak karna termakan usia atau akibat bencana alam dan bangunan yang tidak terpelihara oleh pemiliknya, tidak teraturnya pembangunan rumah (munculnya bangunan modern) yang di karenakan kecenderungan masyarakat yang tidak menggunakan bahan material lokal lagi yang disebabkan oleh beberapa faktor sehingga masyarakat lokal tidak bisa mempertahankan nilai kebudayaan dan sejarah Desa tersebut secara fisik yang memudarkan kekhasan rumah adat yang ada di Desa Bawomataluo. Selain itu dari segi fasilitas, sumber daya masyarakat yang ada saat ini kurang dalam memelihara dan merawat fasilitas pendukung pariwisata sebagai salah satu penunjang kebutuhan wisatawan yang datang ke Desa Bawomataluo dan infrastruktur menuju kawasan Desa Bawomataluo masih sangat minim.

Dari segi aktivitas, saat ini kegiatan kebudayaan cenderung sudah jarang dilakukan atau ditampilkan seperti pertunjukan atraksi khusus untuk wisatawan seperti lompat batu, tari-tarian dan kegiatan lainnya, dimana sekarang ini harus dibayar dulu baru akan ditampilkan atraksi lompat batu atau tari-tarian tersebut. Selain itu pertujukan atraksi budaya yang dipertontonkan tidak berjalan sebagai mana mestinya (misalnya : terjadwalnya pertunjukan atraksi budaya), dimana wisatawan yang datang berkunjung belum tentu bisa menonton atraksi budaya yang ada.

\section{METODE PENELITIAN}

\section{Metode Pengumpulan Data}

Data primer yang dikumpulkan berupa data mengenai kondisi eksisting Desa Bawomataluo, hasil wawancara kepada masyarakat lokal dan pemilik usaha terkait rencana penataan dan tindakan konservasi terhadap bangunan tradisional yang ada. Selain itu kuesioner dibagikan kepada wisatawan untuk mengetahui persepsi dan preferensi wisatawan terhadap kondisi Desa Bawomoataluo sebagai desa wisata budaya dan terkait mengenai rencana penataan fisik Desa Bawomataluo. Penentuan sempel dilakukan dengan menggunakan rumus slovin dan proportion stratified random sampling.

Data sekunder yang didapatkan berupa data-data dari instansi pemerintah seperti BAPPEDA, Dinas Pariwisata, Kantor Kecamatan dan Kepala Desa terkait dengan objek studi seperti data 
RTRW, RPJMD, RDTR, kependudukan, fisik maupun non fisik kawasan dan pengumpulan data melalui internet.

\section{Analisis Data}

Analisis data dilakukan dengan metode deskriptif.

a) Karakteristik potensi dan masalah desa disimpulkan dari hasil analisis kebijakan, analisis daya dukung lingkungan, analisis lokasi dan tapak, dan analisis persepsi dan preferensi. Dimana dari hasil analisis didapatkan SWOT dari Desa Bawomataluo.

b) Untuk hasil penentuan tindakan konservasi terhadap bangunan-bangunan tradisional dan batu megalitik, disimpulkan dari hasil analisis bechmarking (Desa Tenganan dan Desa Penglipuran, Bali), analisis nilai budaya dan analisis konservasi.

c) Analisis kebutuhan ruang merupakan hasil akhir dari rencana penataan Desa Bawomataluo dengan pendekatan konservasi, yang menghasilkan pembagian zonasi desa dalam bentuk masterplan.

Berikut ini kerangka analisis rencana penataan Desa Bawomataluo sebagai desa wisata budaya dengan pendekatan konservasi :

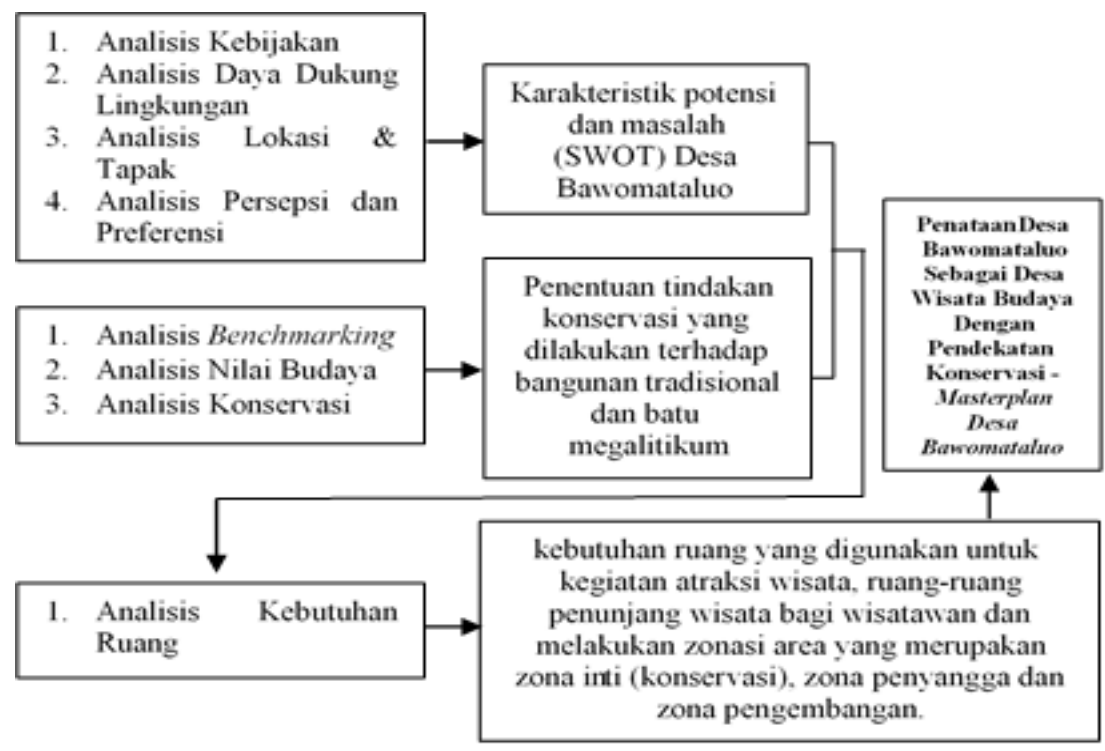

Gambar 1. Kerangka Analisis

Sumber : Hasil Olahan Penulis

\section{HASIL DAN PEMBAHASAN}

\section{Gambaran Umum}

Desa Bawomataluo adalah sebuah representatif dari desa tradisional di Nias Selatan, yang merupakan sebuah desa baru atau desa kedua setelah desa Orahili Fau dihancurkan oleh belanda di pertengahan abad 19. Desa Bawomataluo yang berarti Bukit Matahari sudah ada sejak 300 tahun lalu atau tepatnya pada zaman megalitikum atau batu besar dengan ketinggian 270 meter di atas permukaan laut.

Jumlah penduduk desa Bawömataluo tahun 2015 sebanyak 6.200 jiwa. Sumber penghasilan utama penduduk di Desa Bawomataluo dalam bidang pertanian, pengrajin, dan perkebunan. Penggunaan lahan di Desa Bawomataluo terdiri dari : 
Tabel 1. Penggunaan Lahan

\begin{tabular}{llcc}
\hline No & Penggunaan Lahan & Luas (Ha) & Persentase \\
\hline 1 & Perkarangan (bangunan terbangun) & 15 & $2,1 \%$ \\
\hline 2 & Kebun & 150 & $20,4 \%$ \\
\hline 3 & Hutan & 220 & $29.9 \%$ \\
\hline 4 & Lahan Pertanian & 350 & $47,6 \%$ \\
\hline & TOTAL & $735 \mathrm{Ha}$ & $100 \%$ \\
\hline
\end{tabular}

Sumber : Data Monografi Desa Bawomataluo

Dari tabel diatas, 2,1\% dari total luas wilayah desa merupakan perkarangan (bangunan terbangun).

Memasuki kawasan Desa Bawomataluo, kita akan melewati 77 anak tangga yang tersusun dari bebatuan. Memasuki desa adat dengan deretan rumah adat tradisional di kiri kanan jalan masuk yang terbuat dari susunan lempengan bebatuan yang sekaligus berfungsi sebagai pekarangan. Terdapat sebuah batu setinggi 2,15 meter yang menjadi tempat untuk Fahombo Batu (Lompat Batu), rumah adat dengan atap tinggi menjulang yang disebut Omo Sebua (Rumah Raja) di sebelah kiri dan Bale Pertemuan (Balai Desa) di sebelah kanan. Di Desa Bawomataluo ada istilah omo nifolasara (rumah yang dibentuk seperti satu perahu) yang artinya elemen-elemen spesifik dari kapal laut atau perahu menjadi unsur penting dalam arsitektur rumah adat di Desa Bawomataluo.

Rumah adat terbuat dari kayu yang terbentuk tanpa menggunakan paku dan dibangun di atas tiang yang kuat dari batang kayu (berbentuk rumah panggung) dan atap dilapisi daun rumbia. Rumah-rumah dibangun dengan saling menempel dinding ke dinding dengan rumah-rumah tetangga dan hanya terbuka di depan dan belakang berbentuk seperti rumah deret. Untuk masuk ke dalam rumah adat, terdapat satu tangga sebagai akses masuk ke dalam dua rumah dan di dalam rumah terdapat pintu yang menghubungkan rumah yang satu dengan rumah di sebelahnya yang saling berdempetan. Salah satu keunikan rumah adat di Bawomataluo yang berbentuk deret yaitu kita bisa memasuki rumah dari ujung ke ujung dari dalam rumah adat dengan melewati jalan penghubung setiap dinding rumah. Saat ini terdapat 125 rumah tradisonal yang masih utuh mempertahankan arsitektur bangunan adat.
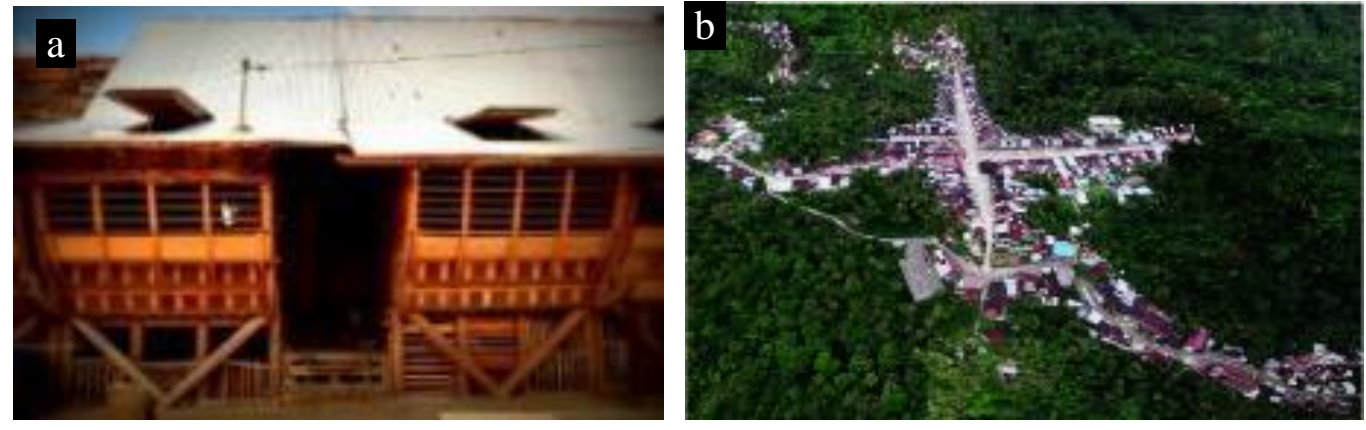

Gambar 2. (a) Rumah Tradisional Desa Bawomataluo ; (b) Lingkup Penelitian Sumber : Observasi Lapangan 


\section{Analisis SWOT}

Tabel 2. Strategi Penataan Desa Bawomataluo

Sumber : Hasil Olahan Penulis

\section{SO-STRATEGY}

Menggunakan kekuatan untuk memanfaatkan peluang :

1. Melestarikan megalitukum dan bangunan-bangunan adat yang menjadi ciri khas Desa Bawomataluo dengan melakukan konservasi sehingga memperkuat daya tarik wisata budaya.

2. Memanfaatkan sejarah desa, kehidupan tradisional, adat istiadat dan barang-barang peninggalan bersejarah untuk dipamerkan di dalam museum.

3. Menguatkan dan mengembangkan wisata budaya dan atraksi wisata

\section{ST-STRATEGY}

Menggunakan kekuatan untuk mengatasi ancaman :

1. Penataan pembangunan Desa Bawomataluo menggunakan mitigasi bencana yang memperhatikan hal-hal mulai dari fisik bangunan, lokasi pengembangan dan jalur evakuasi.

2. Melestarikan bangunan-bangunan rumah adat yang sudah mulai berubah dengan melakukan konservasi.

\section{WO-STRATEGY}

Meminimalkan kelemahan untuk memanfaatkan peluang :

1. Mengembangkan sumber daya manusia untuk mendukung pariwisata yang ada di desa.

2. Meningkatkan dan memperbaiki infrastruktur, jaringan komunikasi, listrik dan sarana prasarana pendukung pariwisata.

3. Mengembangkan pemasaran wisata budaya yang inovatif, kreatif dan efektif.

4. Memperkuat peran pemerintah dalam pengembangan wisata.

\section{WT-STRATEGY}

Meminimalkan kelemahan untuk mengatasi ancaman :

1. Membangun sarana dan prasarana pendukung wisata dilokasi yang kelerengannya $8 \%-45 \%$

2. Lokasi yang memiliki kelerengan $>45 \%$ dimanfaatkan untuk dibangun sebagai ruang terbuka.

3. Meningkatkan peran masyarakat dalam melestarikan bangunan rumah adat dan adat istiadat.

\section{Analisis Konservasi}

Analisis konservasi dilakukan untuk menentukan tindakan konservasi apa yang akan dilakukan, pelaksanaan konservasi dibagi menjadi 2 yaitu : konservasi bangunan tradisional dan konservasi batu peninggalan megalitik.

\section{a. Konservasi Bangunan Tradisional}

Dalam analisis ini terbagi dalam 3 bangunan tradisional yang akan di identifikasi terkait bentuk tindakan konservasi yang akan dilakukan. Untuk menentukan bentuk tindakan konservasi dilihat dari kondisi fisik/fungsi bangunan serta keutuhan dan keasliannya.

\section{Rumah Raja (Omo Sebua)}

Salah satu bangunan bersejarah yang terdapat di Desa Bawomataluo adalah Omo sebua atau rumah raja yang hanya ada satu, karena dibangun hanya untuk kepala kampung (raja) yang secara hirarki ruang bangunan ini mempunyai tempat sangat sentral dan strategis berada di tengah-tengah desa, dengan tinggi bangunan 16 meter. Omo sebua dibangun pada tahun 1886 yang artinya bangunan ini telah berumur kurang lebih 131 tahun.
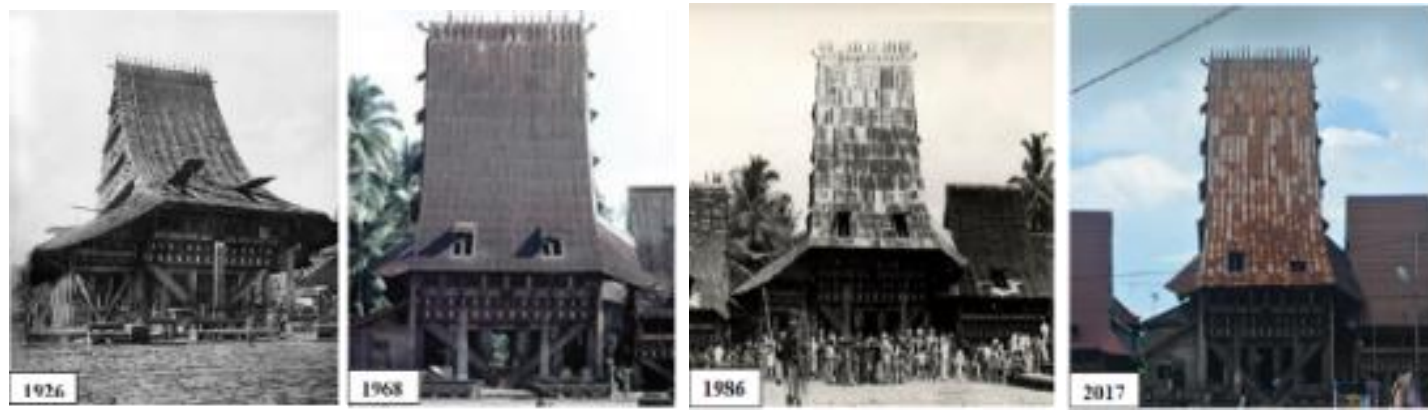

Gambar 3. Timeline Bangunan Omo Sebua

Sumber : https://www.flickr.com/photos/125605764@N04 
Berdasarkan hasil identifikasi keutuhan omo sebua berdasarkan komponen etika konservasi, didapatkan perubahan fisik bangunan pada bagian atap dan material bangunan, perubahan fungsi bangunan pada bagian tengah omo sebua dan terjadi kerusakan struktur bangunan. Selain itu penulis juga mengutip hasil penelitian yang telah dilakukan oleh Tim peneliti dari Universitas Tsukuba, Jepang dan Universitas Gadjah Mada (UGM), yang difokuskan pada pemeriksaan dan pengujian fisik Omo Sebua. Hasil riset menunjukkan kondisi konstruksi rumah sudah sangat rapuh dan material kayu bangunan sudah lapuk. Sehingga tim peneliti menyimpulkan rumah bersejarah itu tak bisa dipertahankan dengan kondisinya saat ini. Harus dibongkar total dan dibangun ulang.

\section{Tindakan Konservasi}

Berdasarkan dari uraian diatas dapat disimpulkan bahwa dari segi keutuhan material, struktur, desain dan arsitektur tidak ada perubahan. Akan tetapi pada konstruksi omo sebua yang hampir semua menggunakan bahan kayu mengalami pelapukan.

Berdasarkan pada kondisi eksisting omo sebua, maka bentuk tindakan konservasi yang akan dilakukan yaitu dengan cara restorasi atau pemugaran. Restorasi yaitu upaya pengembalian kondisi suatu tempat atau fisik bangunan pada kondisi asalnya dengan membuang elemenelemen tambahan dan memasang kembali bagian-bagian asli yang telah rusak atau menurun tanpa menambah unsur/ elemen baru ke dalamnya. Tindakan restorasi didasarkan pada keaslian material, keaslian desain, dan dokumen.

Berikut ini hasil dan pembahasan tindakan konservasi omo sebua yang didasarkan pada Peraturan Daerah Kota Bantung No : 19 Tahun 2009, Pasal 22 tentang Pemugaran.

Tabel 3. Tindakan Konservasi Omo Sebua

\begin{tabular}{|c|c|c|c|}
\hline No & Peraturan Terkait & Kondisi Eksisting & Tindakan Konservasi \\
\hline 1 & $\begin{array}{l}\text { Bagian b : apabila kondisi fisik } \\
\text { bangunan buruk, roboh, terbakar atau } \\
\text { tidak layak harus dibangun kembali } \\
\text { sama seperti semula sesuai dengan } \\
\text { aslinya }\end{array}$ & $\begin{array}{l}\text { konstruksi rumah sudah sangat rapuh dan } \\
\text { material kayu bangunan sudah lapuk. Di } \\
\text { bagian atas ditemukan banyak kayu yang } \\
\text { mengalami kerusakan berat, } 70 \% \text { bagian } \\
\text { bawah rumah kritis dan tidak bisa bertahan } \\
\text { lama. }\end{array}$ & $\begin{array}{l}\text { Bagian bangunan yang rusak/tidak layak } \\
\text { dan mengalami pelapukan direstorasi } \\
\text { kembali menjadi seperti semula sesuai } \\
\text { dengan aslinya. }\end{array}$ \\
\hline 2 & $\begin{array}{l}\text { Bagian c: perawatan dan pemeliharaan } \\
\text { bangunan harus menggunakan bahan } \\
\text { yang sama/sejenis mempertahankan } \\
\text { detail ornamenn bangunan. }\end{array}$ & $\begin{array}{l}\text { Material penutup atap yang harusnya } \\
\text { menggunakan daun rumbia, saat ini } \\
\text { menggunakan seng dan dalam keadaan buruk } \\
\text { (berkarat) dan membutuhkan perbaikan }\end{array}$ & $\begin{array}{l}\text { Penutup atap diperbaiki dan dirawat } \\
\text { menggunakan material awal/aslinya } \\
\text { yang berbahan ringan yaitu daun } \\
\text { rumbia. }\end{array}$ \\
\hline 3 & $\begin{array}{l}\text { Bagian d : dalam upaya revitalisasi } \\
\text { dimungkinkan } \\
\text { penyesuaian/perubahan fungsi tanpa } \\
\text { mengubah bentuk bangunan aslinya }\end{array}$ & $\begin{array}{l}\text { Pada bagian tengan omo sebuah mengalami } \\
\text { perubahan fungsi dari yang semula sebagai } \\
\text { ruang tamu, sekarang sebagai tempat } \\
\text { penyewaan pakaian adat Nias untuk wisatawan }\end{array}$ & $\begin{array}{l}\text { Bagian tengah omo sebuah diubah } \\
\text { fungsinya menjadi bangunan serba guna } \\
\text { yang dapat diakses oleh wisatawan. Hal } \\
\text { ini dilakukan untuk menghidupkan } \\
\text { kembali aktivitas pada omo sebua. }\end{array}$ \\
\hline
\end{tabular}

\section{Sumber : Hasil Olahan Penulis}

\section{Rumah Pertemuan (Omo Bale)}

Saat pembangunan omo sebua pada tahun 1886, setahun kemudian dibanguan Omo Bale. Omo Bale merupakan tempat pertemuan raja dengan warga yang berada di pusat desa tepatnya di 
depan omo sebua. Bangunan Omo Bale didesain tanpa ada penutup disekitar bangunan, hal ini bertujuan agar semua orang bisa melihat kegiatan yang ada di dalam Omo Bale.

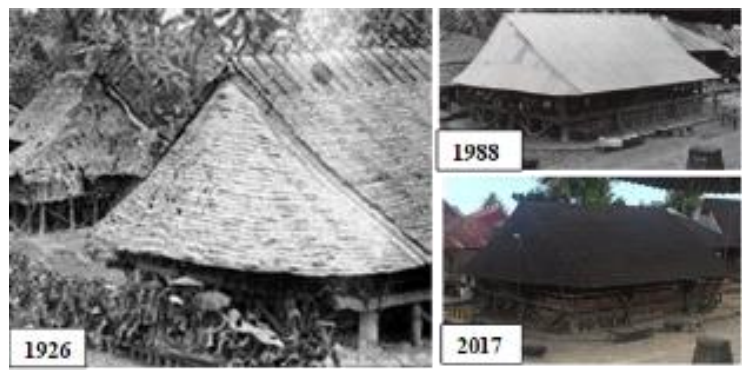

Gambar 4. Timeline Bangunan Omo Bale

Sumber : https://www.flickr.com/photos/125605764@N04

Saat ini kondisi omo bale terlihat tidak terawat, dimana kondisi material utama bangunan yaitu kayu-kayu penyangga/pembentuk bangunan tersebut terlihat usang. Selain itu pada bagian kolong dipenuhi dengan balok-balok kayu yang tidak terpakai, padahal seharusnya bagian bagian kolong tersebut dikosongkan. Kondisi dari omo bale ini sendiri menurunkan nilai estetika dari bangunan tersebut.

\section{Tindakan Konservasi}

Dari semua bangunan adat yang terdapat di Desa Bawomataluo, omo bale merupakan satusatunya bangunan yang pernah dilestarikan atau di konservasi. Tepatnya pada tahun 2012 dilakukan restorasi (pemulihan kembali) omo bale oleh Kepala Desa yang didukung oleh Multi Donor Fund. \& International Labour Organization. Pemulihan yang dilakukan diantaranya penggantian atap menggunakan bahan yang waterproof dengan warna yang disesuaikan seperti daun rumbia, beberapa material kayu penyangga ditukar dengan balok kayu yang baru, perbaikan pada beberapa struktur bangunan dan yang terakhir pengecatan pada bagian luar bale.

Berdasarkan dari tindakan restorasi yang sebelumnya sudah dilakukan dan pada kondisi eksisting bale dalam keadaan tidak terawat. Maka tindakan konservasi yang akan dilakukan yaitu melakukan tindakan pencegahan kerusakan (konservasi secara langsung). Pencegahan dilakukan untuk mencegah omo bale terpengaruh dengan lingkungannya sehingga tidak menimbulkan pembusukan ataupun kerusakan. Tindakan pencegahan yang dilakukan diantaranya pengontrolan internal seperti kelembaban, suhu, cahaya, kebersihan, pemeliharaan, pembersihan, dan manajemen ini dilakukan secara rutin.
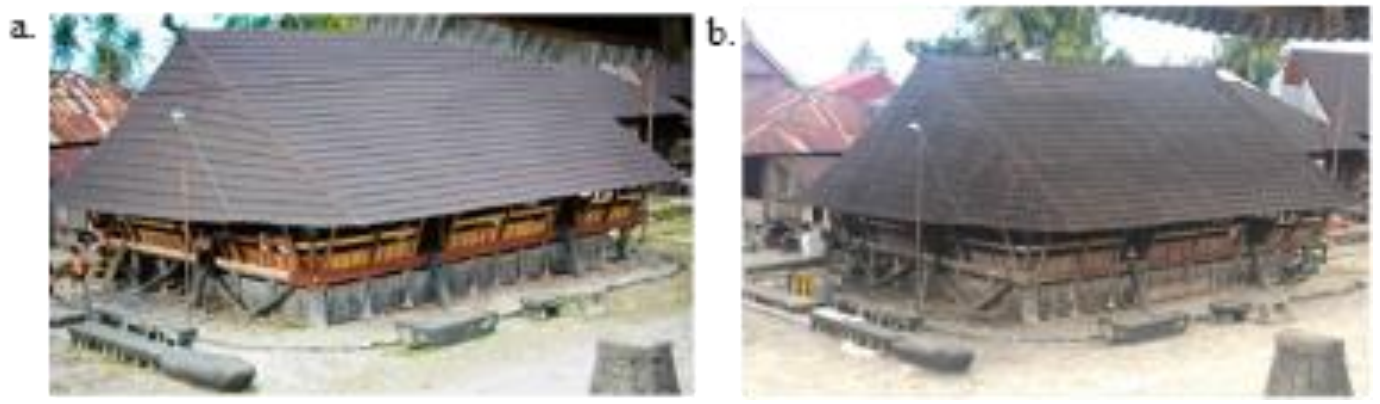

Gambar 5. (a) Bale Setelah di Restorasi Tahun 2012 ; (b) Kondisi Bale Saat Ini Tahun 2017 Sumber : Observasi Lapangan 


\section{Rumah Tradisional (Omo Hada)}

Saat ini di Desa Bawomataluo terdapat 251 rumah yang terdiri dari rumah adat tradisional (Omo Hada) dan rumah melayu/rumah beton (bukan rumah tradisional). Dalam menentukan tindakan konservasi terhadap 251 rumah tersebut, dilakukan identifikasi keutuhan konservasi setiap rumah berdasarkan pada kriteria/komponen keutuhan konservasi bangunan (jenis bangunan, fisik luar bangunan, struktur kayu, desain banguanan, estetika, arsitektur dan fungsi bangunan. Klasifikasi konservasi dibagi menjadi 3 tingkatan yaitu :

a. Konservasi Ringan (Gol. A) : berbentuk omo hada, material atap menggunakan seng, terdapat penggunaan beton pada tampak depan bangunan dan tidak ada perubahan lainnya.

b. Konservasi Sedang (Gol.B) : berbentuk omo hada / rumah melayu material atap menggunakan seng, terdapat penggunaan beton pada tampak depan bangunan dan perubahan fungsi bangunan menjadi tempat usaha.

c. Konservasi Berat (Gol. C) : berbentuk rumah melayu / rumah beton, fisik luar dan struktur bangunan tidak menggunakan bahan kayu, terjadi perubahan desain, estetika arsitektur dan fungsi bangunan.

Dari hasil identifikasi, didapatkan hasil :

- Konservasi Ringan (Gol. A) = 125 rumah

- Konservasi Sedang (Gol. B) $=68$ rumah

- Konservasi Berat (Gol. C) $=58$ rumah

\section{Tindakan Konservasi}

- Konservasi Ringan (Gol. A)

Bentuk tindakan konservasi yang dilakukan yaitu dengan cara restorasi. Bentuk tindakan restorasi yang dilakukan antara lain : mengganti penutup atap yang menggunakan seng ke material aslinya yaitu daun rumbia. Dilakukan tindakan restorasi dengan mengganti penggunaan material beton yang terdapat dibagian depan rumah ke material aslinya dengan menggunakan bahan-bahan lokal yaitu : ehomo (penyanggah struktur bangunan tradisional berbentuk balok bulat dan menggunakan material kayu) dan ndriwa (tiang kayu bulat).

\section{- Konservasi Sedang (Gol. B)}

Rumah melayu yang terdapat di Desa Bawomataluo menggunakan material kayu sebagai struktur dari bangunan tersebut, hal ini menjadi pertimbangan dalam penentuan tindakan konservasi yang ada. Bentuk tindakan konservasi yang dilakukan yaitu dengan cara restorasi yaitu : bentuk desain dan estetika arsitektur rumah melayu diubah ke bentuk aslinya, mengikuti desain Omo Hada yang arsitekturnya berbentuk seperti lasara (perahu). Material yang digunakan menggunakan bahan lokal yang diperuntukan untuk bangunan rumah tradisional.

\section{- Konservasi Berat (Gol. C)}

Dari hasil yang didapatkan terdapat 58 rumah yang berbentuk rumah beton. Kemungkinan untuk mengembalikan bangunan tersebut kebentuk asli rumah adat tradisional akan memakan biaya yang besar dikarenakan hampir semua struktur dan arsitekturnya menggunakan material beton. Untuk menangani hal ini bisa dilakukan dengan tindakan konservasi dengan cara adaptif re-use. Tindakan ini bisa dilihat seperti yang diterapkan oleh salah satu objek pembanding yaitu Desa Penglipuran, dimana bambu menjadi material utama bangunan yang terdapat disana. Bangunan 
baru yang menggunakan material beton yang ada di desa penglipuran, mereka melakukan tindakan konservasi adaptif re-use dengan cara menempelkan ornamen bambu pada dinding beton tersebut.

Hal ini dapat diterapkan pada pada rumah beton yang terdapat di Desa Bawomataluo. Bentuk tindakan adaptif re-use dilakukan dengan cara :

- Pada tampak depan rumah beton, diberikan tempelan dinding yang bermotif kayu, untuk mewujudkan keseragaman bangunan dan menunjukan lokalitas dari penggunaan bahan bangunan kayu.

- Mengganti penutup atap yang menggunakan seng ke material aslinya yaitu daun rumbia.
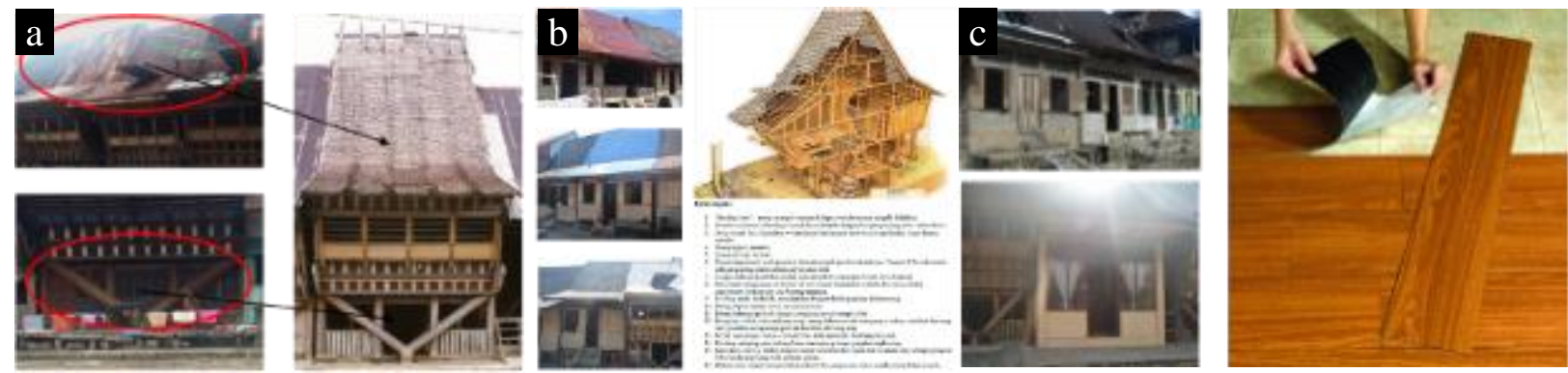

Gambar 6. (a) Restorasi Gol. A ; (b) Restorasi Gol. B ; (c) Adaptif re-use Gol. C Sumber : Observasi Lapangan dan Hasil Olahan Penulis

\section{b. Konservasi Batu Megalitik}

Bentuk tindakan konservasi batu megalitik berbeda dengan tindakan konservasi bangunan. Dalam konservasi cagar budaya berbahan batu bentuk tindakan konservasi dapat dilakukan melalui langkah preventif dengan konservasi preventif (pencegahan) dan langkah kuratif dengan konservasi kuratif (penanggulangan atau perawatan). Beberapa batu megalitik di Desa Bawomataluo mengalami kerusakan (damage) yaitu dimana suatu struktur telah kehilangan sebagian atau semua kekuatannya yang ditandai oleh retak, hancur, lepasnya komponenkomponen. Serta mengalami pelapukan (deterioration) yaitu perubahan material yang biasanya menuju pada berkurangnya ketahanan, meningkatnya kerapuhan, meningkatnya prorositas, dan hilangnya material yang biasanya dimulai dari luar dan bekerja ke dalam material. Dan pelapukan utamanya disebabkan oleh aksi fisik, kimia dan biologi.
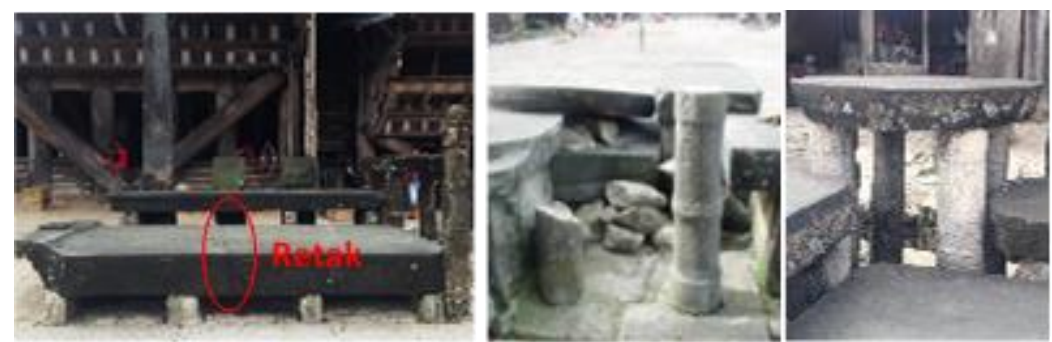

Gambar 7. Batu Megalit di depan Omo Sebua Retak, Hancur dan Mengalami Pelapukan Sumber : Observasi Lapangan dan Hasil Olahan Penulis 

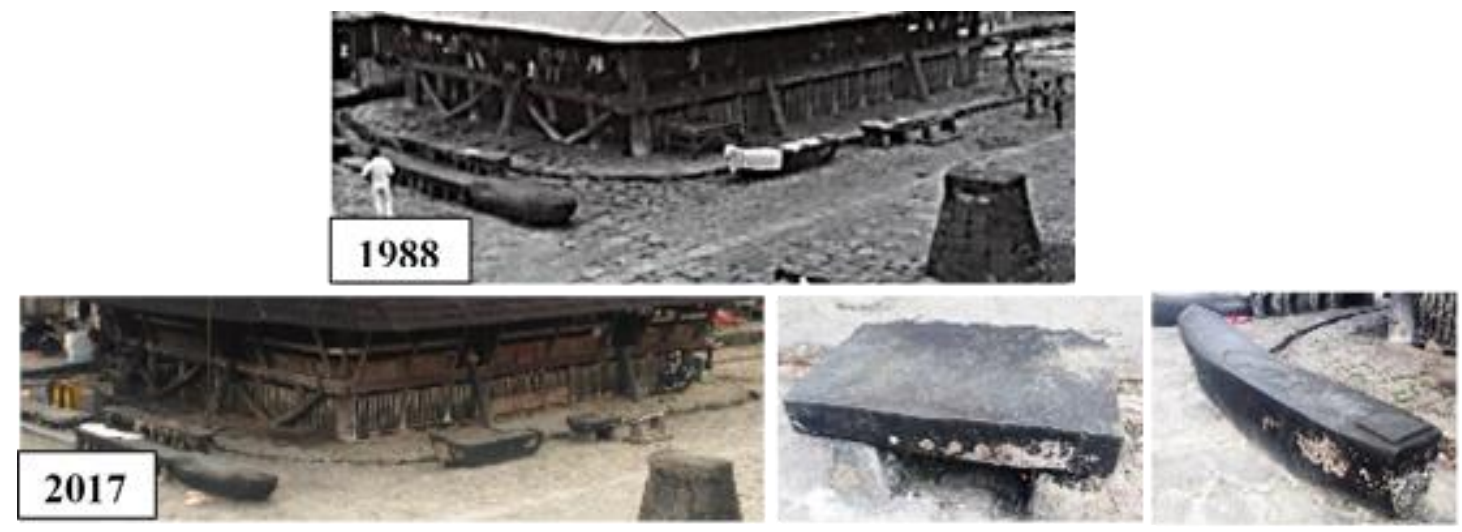

Gambar 8. Kondisi Batu Megalit di Depan Omo Bale yang Mengalami Pelapukan Sumber : Observasi Lapangan dan Hasil Olahan Penulis

\section{Tindakan Konservasi}

Bentuk tindakan konservasi batu megalitik yang terdapat di Desa Bawomataluo menggunakan tindakan konservasi yang bersifat aktif meliputi pembersihan, konsolidasi dan pelapisan permukaan.

- Dilakukan pembersihan permukaan yang kotor pada batu megalitik untuk perbaikan.

- Konsolidasi diperlukan untuk memulihkan kekuatan batu akibat pelapukan dan diharapkan dapat mencegah kerusakan lebih lanjut.

- Pelapisan permukaan (surface coating), mencakup berbagai bahan yang diaplikasikan pada permukaan batu.

\section{Analisis Kebutuhan Ruang}

- Zona I (Inti - Konservasi), merupakan zona yang di konservasi tidak mengalami perubahan atau penambahan ruang. Terdiri dari perkampungan adat Desa Bawomataluo dengan luas area 5 ha, yang terdapat objek konservasi yaitu 260 rumah adat (omo hada), satu rumah raja (omo sebua), satu bale pertemuan dan batu-batu peninggalan megalit yang tersebar di perkampungan.

- Zona II (Penyangga), merupakan zona yang menjadi pendukung dari zona inti. Terdiri dari rumah-rumah penduduk yang berada diluar zona inti, tempat pemandian dan fasilitas wisata budaya yang didalamnya terdapat rencana pembangunan museum sejarah (ruang pameran, pusat edukasi dan bale atraksi/pertunjukan). Luas zona penyangga yaitu 6,9 ha, dan rencana pembangunan museum membutuhkan luas 0.156 ha.

- Zona III (Pengembangan) merupakan zona untuk pengembangan sosial ekonomi masyarakat dan sosial ekonomi budaya dengan luas area 4,7 ha. Berdasarkan pada hasil perhitungan kebutuhan ruang yang dibutuhkan pada zona ini sebesar 0.175 ha. Beberapa rencana penambahan ruang yaitu ; loket, pusat informasi, toilet, tempat parkir, restoran, toko sovenir, mushola dan klinik kesehatan. 
Tabel 4. Kebutuhan Ruang Desa Bawomataluo Sebagai Desa Wisata Budaya

\begin{tabular}{|c|c|c|c|c|c|c|c|c|c|c|c|}
\hline Zona & $\begin{array}{l}\text { Sub } \\
\text { Zona }\end{array}$ & Nema Zona & Kapasittes & $\begin{array}{c}\text { Jumiah } \\
\text { Unit }\end{array}$ & $\begin{array}{l}\text { Luas } \\
\text { Bacgunaa } \\
(m 2)\end{array}$ & $\begin{array}{l}\text { Luak } \\
\text { Ruang } \\
\text { Luar (m2) }\end{array}$ & $\begin{array}{c}\text { Tetal Luas } \\
\text { Lantai } \\
\text { Bangunan (m2) }\end{array}$ & $\begin{array}{c}\text { Total Luar Rasng } \\
\text { yang Luar } \\
\text { Dikerwbangkat ( }=2)\end{array}$ & $\begin{array}{l}\text { Ser+Sir } \\
(20 \%)\end{array}$ & $\begin{array}{l}\text { Total Area } \\
\text { Peagembangan } \\
\text { (m2) }\end{array}$ & $\begin{array}{l}\text { Lues Aret } \\
\text { (Hs) }\end{array}$ \\
\hline \multirow{17}{*}{$\begin{array}{c}\text { III } \\
\text { Pengembangan }\end{array}$} & A & Zena Peanrims & & & & & & & & & \multirow{17}{*}{$4.7 \mathrm{Ka}$} \\
\hline & 1 & Gate Masule & - & 1 & - & 10 & - & 10 & 2 & 12 & \\
\hline & 2 & Loket & 3 & 1 & 12 & - & 12 & - & 2.4 & 14.4 & \\
\hline & 3 & Pastit Infoemeni & 4 & 1 & 10 & $=$ & 10 & 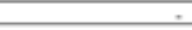 & 2 & 12 & \\
\hline & & Tempon Peauharan & & & & & & & & & \\
\hline & 4 & Uang & 10 & 1 & 25 & $=$ & 25 & $=$ & 5 & 30 & \\
\hline & 5 & Parki & $=$ & 1 & $\therefore$ & 798 & $\therefore$ & 798 & 159.6 & 957.6 & \\
\hline & 6 & Pos Kezenanan & 2 & 2 & 8 & - & 16 & - & 3.2 & 19.2 & \\
\hline & 7 & Teiles & 3 & 1 & 17,6 & - & 17.6 & - & 3.52 & 21.12 & \\
\hline & B & Zema Akomodasi & & & & & & & & & \\
\hline & 1 & $\begin{array}{l}\text { Restawnaut/Rafe- } \\
\text { kafn }\end{array}$ & 20 & 10 & 40 & 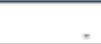 & 400 & . & 30 & 480 & \\
\hline & & Toko Souvenir dias & & & & & & & & & \\
\hline & 2 & Elontonran & 20 & 20 & 19.2 & $=$ & 384 & $\therefore$ & 76.8 & 450.8 & \\
\hline & 3 & Klinik Kesehaten & 10 & 1 & 40 & - & 40 & 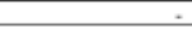 & 8 & 48 & \\
\hline & 4 & Musbolla & $\because$ & 1 & 25 & - & 25 & $\because$ & 5 & 30 & \\
\hline & 5 & Toiles & 3 & 1 & 17.6 &. & 17.6 &. & 3.52 & 21.12 & \\
\hline & Total & Area Pengembangan & & & & & 2106.44 & & & & \\
\hline \multirow{6}{*}{$\begin{array}{c}\text { II } \\
\text { Petyangga }\end{array}$} & 1 & Museum Sejarah & & & & & & & & & \multirow{6}{*}{$6.9 \mathrm{Ha}$} \\
\hline & & Pastrt Edukani & $=$ & $=$ & 84 & $=$ & $=$ & . & 16.8 & 1008 & \\
\hline & & $\begin{array}{l}\text { Ruang Penpimpenan } \\
\text { Kolekai }\end{array}$ & & - & & & & & & & \\
\hline & & $\begin{array}{l}\text { Koleksi } \\
\text { Restat Parerna }\end{array}$ & $100 \mathrm{~K}=0$ & $\overline{1}$ & $\frac{150}{566}$ & - & - & - & 30 & $\frac{180}{6790}$ & \\
\hline & & $\begin{array}{l}\text { Ruang Pameras } \\
\text { Ruand Pertunjulan }\end{array}$ & $100 \mathrm{Kaxyz}$ & 1 & 566 & 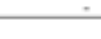 & $=$ & - & 113.2 & 679.2 & \\
\hline & & $\begin{array}{l}\text { Rewang Pertunjulan } \\
\text { Outrioor }\end{array}$ & - & - & 500 & - & $=$ & 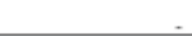 & 100 & 600 & \\
\hline
\end{tabular}

Sumber : Hasil Olahan Penulis

\section{Rencana Penataan}

Berikut ini merupakan uraian rencana dan arahan penataan Desa Bawomataluo dengan pendekatan konservasi :

\section{Tabel 5. Rencana dan Arahan Penataan Desa Wisata Budaya Bawomataluo}

\begin{tabular}{|c|c|}
\hline Rencana & Arahan \\
\hline Pengelolaan & $\begin{array}{l}\text { Adanya lembaga asosiasi pariwisata Desa Bawomataluo yang merupakan suatu organisasi nirlaba yang berdasarkan pada } \\
\text { kolaborasi antara pemerintah dan penduduknya. }\end{array}$ \\
\hline Arahan Promosi & $\begin{array}{l}\text { Bekerjasama dengan Tour Operator yang menangani kegiatan wisata buday serta meningkatkan promosi dan layanan } \\
\text { informasi terpadu tentang program wisata budaya di Desa Bawomataluo. }\end{array}$ \\
\hline $\begin{array}{l}\text { Pengendalian } \\
\text { bencana alam }\end{array}$ & $\begin{array}{l}\text { 1. Mempertahankan fungsi bangunan awal dari rumah tradisional yang berbentuk rumah panggung, } \\
\text { 2. Membatasi pengembangan kawasan terbangun di daerah longsor } \\
\text { 3. Penyediaan pos-pos bencana apabila terjadi longsor } \\
\text { 4. Mengurangi tingkat keterjalan lereng } \\
\text { 5. Menghindai pembangunan di daerah yang rawan longsor. } \\
\text { 6. Mendirikan bangunan harus dengan fondasi yang kuat. } \\
\text { 7. Melakukan pemadatan tanah disekitar perumahan. }\end{array}$ \\
\hline $\begin{array}{l}\text { Pengendalian } \\
\text { bangunan } \\
\text { tradisional }\end{array}$ & $\begin{array}{l}\text { 1. Bentuk bangunan sebagai bentuk arsitektur asli, warna arsitektur alami (material alami), material kayu untuk struktur } \\
\text { dan konstruksi utama (lantai, dinding, pintu jendela dan tangga) } \\
\text { 2. Atap bangunan mempertahankan bentuk, material asli, material kayu untuk struktur \& konstruksi utama atap. } \\
\text { 3. Sub-struktur bangunan harus dikembalikan ke kondisi dan fungsi sebelumnya dalam hal struktur, konstruksi dan } \\
\text { penggunaan setiap fungsi ruang. }\end{array}$ \\
\hline $\begin{array}{l}\text { Pengendalian } \\
\text { ruang terbuka }\end{array}$ & $\begin{array}{l}\text { Alun-alun yang merupakan ruang terbuka yang merupakan jalan utama di desa, harus dipertahankan dalam hal } \\
\text { peninggalan budaya megalitikum batu asli dan bangunan tradisional yang menjadi lanskap asli bawomataluo, untuk itu } \\
\text { perlu dilakukan pemindahan/penghilangan obyek fisik (tiang listrik, perluasan bangunan kearah depan dan pemasangan } \\
\text { drainase) obyek non fisik (pakaian, warung makan dan minuman) yang mengganggu lanskap asli bawomataluo. }\end{array}$ \\
\hline $\begin{array}{l}\text { Pengendaliam } \\
\text { Desa } \\
\text { Bawomataluo } \\
\text { sebagai } \\
\text { kawasan cagar } \\
\text { budaya }\end{array}$ & $\begin{array}{l}\text { 1. Arahan Mikro Spasial } \\
\text { a. Menata sekitar ikon kawasan (Desa Adat Bawomataluo) agar mudah dilihat dari segala arah } \\
\text { b. Peningkatan pemeliharaan melalui perawatan cagar budaya agar tidak rusak } \\
\text { c. Memperbaiki tempat parkir yang ada di kawasan kawasan cagar budaya } \\
\text { d. Membangun sarana akomodasi pada zona pengembangan yang telah disesuaikan dengan kebijakan } \\
\text { e. Menyediakan sarana pariwisata berupa gedung kesenian, museum dan galeri cinderamata } \\
\text { f. Membangun sarana pendukung pada zona pengembangan yang telah disesuaikan dengan kebijakan } \\
\text { g. Menjaga bentuk dan struktur bangunan-bangunan adat yang ada } \\
\text { h. Menjaga bentukan pola ruang dari desa-desa adat yang telah ada } \\
\text { i. Meningkatkan aksesbilitas menuju desa-desa adat } \\
\text { 2. Arahan Mikro Non-Spasial } \\
\text { a. Penyeragaman informasi sejarah dengan membuat dokumentasi untuk mendukung kegiatan pariwisata. } \\
\text { b. Peningkatan ragam seni budaya di lokasi cagar budaya } \\
\text { c. Kerjasama dengan komunitas pecinta budaya untuk optimalisasi atraksi } \\
\text { d. Menghidupkan kembali atraksi budaya yang telah punah } \\
\text { e. Pengadaan event untuk atraksi budaya secara berkala } \\
\text { f. Memberikan pelatihan khusus bahasa inggris kepada juru pelihara } \\
\text { g. Memberikan seragam pada semua juru pelihara di kawasan cagar budaya }\end{array}$ \\
\hline
\end{tabular}


Berdasarkan pada hasil programming atau kebutuhan ruang yang sudah dilakukan dihasilkan masterplan Desa Bawomataluo yang terbagi atas zona konservasi, zona penyangga dan zona pengembangan. Rencana penataan secara umum (masterplan) Desa Bawomataluo sebagai desa wisata budaya dapat dilihat pada lampiran.

\section{KESIMPULAN DAN SARAN}

\section{Kesimpulan}

a. Peningkatan infrastruktur sarana dan prasarana yang menunjang aksesibilitas kawasan Desa Bawomataluo. Penambahan beberapa fasilitas penunjang wisata dan perbaikan kualitas dari kondisi eksisting dari setiap fasilitas

b. Pembangunan bangunan di kawasan Desa Bawomataluo dengan memperhatikan lokalitas masyarakat setempat dan menggunakan material-material yang ramah lingkungan.

c. Penataan desa dengan pendekatan konsevasi menghasilkan bentuk tindakan konservasi terhadap cagar budaya (bangunan tradisional) dan batu megalitik, antara lain :

1. Konservasi Bangunan Tradisional

- Rumah Raja (Omo Sebua) : dilakukan tindakan restorasi.

- Bale Pertemuan (Omo Bale) : dilakukan tindakan pencegahan kerusakan / konservasi secara langsung terhadap bangunan agar tidak terpengaruh dengan kondisi lingkungan disekitarnya.

- Rumah Masyarakat (Omo Hada) : dibagi dalam tiga klasifikasi konservasi yaitu konservasi ringan (golongan A), sedang (golongan B) dan besar (golongan C). Dengan bentuk tindakan konservasi yang dilakukan yaitu dengan cara restorasi dan adaptif re-use.

2. Konservasi Batu Peninggalan Megalit

Semua batu-batu peninggalan megalit yang terdapat di depan omo sebua, omo bale dan tersebar di depan omo hada, dilakukan tindakan konservasi yang bersifat aktif yaitu bentuk tindakan konservasi yang langsung ke batu megalit.

d. Desa Bawomataluo dibagi dalam tiga zona, yaitu zona inti, penyangga dan pengembangan.

- Zona Inti (konservasi), terdiri dari perkampungan adat Desa Bawomataluo.

- Zona Penyangga, terdiri dari rumah-rumah penduduk yang berada diluar zona inti, tempat pemandian dan museum sejarah.

- Zona Pengembangan, untuk pengembangan sosial ekonomi masyarakat dan sosial ekonomi budaya seperti restaurant atau kafe-kafe, toko souvenir dan lain-lain.

\section{Saran}

Saran yang didapat dari penilitian ini adalah sebagai berikut :

a. Kelembagaan pengelolaan desa wisata melibatkan kelembagaan masyarakat setempat atau tokoh-tokoh adat.

b. Perlu adanya peraturan yang pasti terkait pelestarian cagar budaya yang terdapat di Desa Bawomataluo, khususnya bagi masyarakat yang tinggal di desa.

c. Masyarakat lokal mengembangakan komponen-komponen kebudayaan yang terdapat di desa dan menjadikan hal tersebut sebagai sumber pendapatan yang bisa ditampilkan atau dijual kepada para wisatawan yang datang ke Desa Bawomataluo.

d. Pemerintah Daerah lebih memperhatikan proses dan hasil dari pengerjaan pembangunan infrastruktur di Desa Bawomataluo.

e. Pemerintah dan masyarakat setempat meningkatkan kegiatan promosi Desa Bawomataluo sebagai destinasi utama wisata budaya di Nias Selatan, melalui media informasi seperti website, free map, dan membuat paket-paket wisata. 


\section{REFERENSI}

Ari, S. (2011, Juli 25). Teori Konservasi Kayu. p. 1.

Atmaja, Y. (2002). Ekowisata Rakyat : Liku-Liku Ekowisata di Tenganan. Kuta: Wisnu Press.

Aylin, O. (2008). Architectural Conservation : Blackwell Publishing.

Burtenshaw, D. (1991). In The European City : Western Perspective (pp. 157-158). New York: David Fulton Publisher.

Desa Bawomataluoh, Nias Selatan https://www.scribd.com/document/323685387

Dwijendra, K. (2009). Arsitektur dan Kebudayaan Bali Kuno. Denpasar: Udayana Univ Pr.

Feilden, B. (1994). Conservation on Historic Building. Great Britain: Butterworth Architecture.

Gayatri, P. G., \& Pitana, G. I. (2005). Sosiologi Pariwisata. Yogyakarta: Andi.

Harastoeti, D. (2011). 100 Bangunan Cagar Budaya di Bandung . Bandung: CSS Publishing.

ICOMOS. (1999). The Burra Charter. Australia: ICOMOS Inc.

ICOMOS, I. C. (1981). International Charter for the Conservation and Restoration of Monuments. Australia: ICOMOS.

Inskeep, E. (1991). Tourism Planning, An Integrated and Sustainable Development Approach. New York: Van Nostrand Reinhold.

Jogja, S. H. (2009). Pedoman Pelestarian Pasca Bencana Kawasan Pusaka Kotagede Yogyakarta, Indonesia. Yogyakarta: GONG Grafis.

KA, D. (2009). Arsitektur dan Kebudayaan Bali Kuno. Denpasar: Udayana Universitas Pr.

Mada, U. G., \& Tsukuba, U. (2013). Draf Master Plan Pelestarian Bawomataluo. Indonesia dan Jepang: Komisi Nasional Jepang untuk UNESCO.

McKercher, B., \& Cros, H. d. (2002). Cultural Tourism: The Partnership Between Tourism and Cultural Heritage Management. New York: The Haworth Hospitality Press.

Nias, Y. P. (2017, April 26). Museum Pusaka Nias. Retrieved from http://www.museumnias.org/arsitektur-nias/

Nuryanti, W. (1993). Concept, Perspective and Challenges. Naskah Lengkap Laporan Konferensi Internasional tentang Pariwisata Budaya. Yogyakarta: Gadjah Mada University Press.

Peraturan Daerah DKI Jakarta Nomor 09 Tahun 1999 tentang Pelestarian dan Pemanfaatan Lingkungan dan Cagar Budaya

RDTRK (2014). Tentang Penyusunan RDTRK dan Zonasi Kecamatan Fanayama.

Richards, G., \& Munsters, W. (2007). Culture Tourism Research Methods . London, UK: CABI.

RIPARDA (2014). Tentang Kepariwisataan Kabu paten Nias Selatan dan Kecamatan Fanayama, Desa Bawomataluo.

R.M. Warner, S. G. (1978). New Profit from Old Building. New York.

RPJMD (2016-2021). Tentang Kabupaten Nias Selatan dan Kecamatan Fanayama.

RTRW (2014-2034). Tentang Kabupaten Nias Selatan dan Kecamatan Fanayama.

Society, J. H. (2009). Pedoman Pelestarian Pasca Bencana Kawasan Pusaka Kotagede Yogyakarta, Indonesia. Yogyakarta: GONG Grafis.

The Fine Art Department of Thailand, 1999. Cultural System: For Quality Management,Bangkok, Thailand

Undang Undang Republik Indonesia No 10 tahun 2009 tentang Kepariwisataan

Undang-Undang Nomor 11 Tahun 2010.LN. Tahun 2010 No. 130, TLN. Tahun 2010 No. 5168. Undang-Undang tentang Cagar Budaya,

Yoeti, O. (1996). Pengantar Ilmu Pariwisata. Bandung: Angkasa.

Yoeti, O. (2002). Perencanaan Strategis Pemasaran Daerah Tujuan Wisata. Jakarta: Pradnya Paramita. 